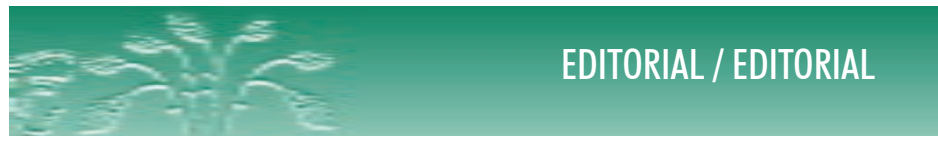

DOI: 10.12957/demetra.2016.25441

\title{
Alimentação, corpo, gênero e subjetividade
}

\section{Food, body, gender and subjectivity}

Neste número, DEMETRA: Alimentação, Nutrição छ́ Saúde reúne artigos que articulam os temas "alimentação", "corpo", "gênero" e "subjetividade". Tal iniciativa foi gestada a partir das reflexões realizadas no âmbito de três Programas de Pós-graduação: Alimentação, Nutrição e Saúde, da Universidade do Estado do Rio de Janeiro (UERJ); Ensino em Biociência e Saúde, do Instituto Oswaldo Cruz (IOC), da Fundação Oswaldo Cruz (FIOCRUZ); e Nutrição, da Universidade Federal do Rio de Janeiro (UFRJ), por meio da oferta de disciplinas comuns e do intercâmbio entre docentes, que incluem a parceria com a Universidade Federal Rural do Rio de Janeiro (UFRRJ).

Temos observado, ao longo do tempo, um crescente interesse acadêmico pelos estudos sobre alimentação/cultura e corpo/gênero. No entanto, tais categorias têm sido abordadas isoladamente nos distintos campos do saber, sobretudo no âmbito da Nutrição, no qual as pesquisas que tematizam alimentação e cultura prevalecem comparativamente àquelas sobre corpo e gênero. Portanto, permanece como um desafio para as pesquisas em Alimentação e Nutrição a incorporação das categorias analíticas "corpo e gênero" como uma das dimensões na análise da cultura envolvendo a comensalidade, ainda que estudos voltados para mulheres e homens já tenham sido tradicionalmente considerados.

"Corpo" e "gênero" são categorias recorrentes na prática social e no senso comum, ao mesmo tempo que fazem parte de uma estratégia de recorte teórico-conceitual no âmbito das Ciências Sociais. Por meio deste arcabouço, pretendeu-se problematizar e potencializar a definição desses conceitos nas pesquisas voltadas à Alimentação e Cultura. O objetivo foi assinalar como tais conceitos apontam para uma relevante dimensão da realidade social, já que, historicamente, as diferenças relativas à construção das identidades sociais no que tange ao gênero e à sexualidade nem sempre estiveram presentes na construção do conhecimento científico. Por meio do acionamento destas diferenças, reitera-se o fato de a vida social ser constituída em variadas dimensões, tais como o tempo e o espaço, que assim como a comensalidade e as relações entre os sexos, são sancionados 
socialmente. A diferença entre os sexos, neste sentido, também exprime os valores que organizam a vida em sociedade e é produzida por ela, estando muitas vezes expressa no entrelaçamento destas dimensões, o que nos interessa explorar.

Este número temático se dedica, portanto, às relações entre ALIMENTAÇÃO, CORPO, GÊNERO E SUBJETIVIDADE como construções sociais, que perpassam não só a experiência de vida cotidiana, mas também os modos de fazer ciência e o desenvolvimento científico e tecnológico em saúde.

Os trabalhos que integram este temático correspondem a pesquisas empíricas e/ou teóricas, sobretudo aquelas que destacam a problemática do corpo gendrificado como modeladores da subjetividade. Neste esforço, pretendeu-se reunir trabalhos que apontem possíveis interfaces, entre um ou mais destes termos interligados, tendo em vista a incidência dos nexos entre corpo, relações de gênero e subjetividade no cotidiano das práticas alimentares e de saúde da sociedade contemporâneas. No seu conjunto, apresentam diferentes perspectivas analíticas (históricas, sociológicas, antropológicas ou psicológicas) que favorecem tais associações.

Foram selecionadas pesquisas e/ou ensaios que discutem o caráter social e cultural da alimentação em termos de normatizações, regulações e/ou naturalizações do corpo, com implicações para a existência individual e coletiva, a saber: concepções e práticas com referência à construção e imagem corporal, incluindo os transtornos alimentares ligados à obesidade e à anorexia; reprodução social por meio da análise dos processos de amamentação e da crítica às abordagens contemporâneas envolvendo família e diversidade sexual no que tange à construção das identidades sociais; práticas de ensino ligadas ao corpo e ao gênero em diferentes contextos educativos; processos de trabalho, formação e identidade profissional e comensalidade. Todos estes aspectos são contemplados em diferentes cenários de pesquisas, incluindo a produção midiática, cinematográfica e as artes.

Cabe destacar que, embora alguns trabalhos não tomem a comensalidade como eixo central da análise, eles têm o mérito de problematizar e potencializar a definição desses conceitos no campo da Alimentação e Cultura. Mas nota-se que o que aqueles têm em comum com este último diz respeito aos complexos processos de intervenções biomédica e/ou tecnológicas e medicalização, como um amplo processo social do corpo gendrificado, cujas legislações/normativas e políticas/ institucionalizações repercutem nas experiências subjetivas. Destacamos também que parte da produção aqui reunida associa gênero a sexo - mais próximo a uma compreensão biologicista dos corpos a partir do dimorfismo sexual - avançando pouco na discussão conceitual já consagrada no âmbito das Ciências Sociais. No entanto, optamos por acolhê-los por compreendermos a importância de estimular a continuidade e avanço das análises sobre esses temas no campo da Alimentação e Nutrição, considerando ainda o caráter incipiente dessas reflexões em termos da produção mais geral no campo, como já assinalamos. 
Consideramos, por fim, termos alcançado uma boa aceitação desta iniciativa, dado o elevado número de artigos recebidos, o que pode ser considerado um interesse pela temática. Para nós, além de gratificante, foi a oportunidade de apresentarmos os possíveis nexos da Alimentação e Cultura com as temáticas "corpo", "gênero" e "subjetividade", configurados historicamente como dispositivos de produção de verdades sobre si e os outros, já apontados pela literatura antropológica e sociológica.

Observamos, pelo esforço empreendido, a existência de significativas diferenças relativas ao gênero nos mais variados processos de intervenção nos corpos, o que cabe refletir.

Os Organizadores

Eliane Portes Vargas (Fundação Oswaldo Cruz)

Luciane Moás (Universidade Federal Rural do Rio de Janeiro)

Francisco Romão Ferreira (Universidade do Estado do Rio de Janeiro)

Fabiana Bom Kraemer (Universidade do Estado do Rio de Janeiro)

Cristiane Marques Seixas (Universidade do Estado do Rio de Janeiro) 
